\title{
Submillimeter and Microwave Residual Losses in Epitaxial Films of $\mathrm{Y}-\mathrm{Ba}-\mathrm{Cu}-\mathrm{O}$ and Tl-Ca-Ba-Cu-O
}

\author{
D. Miller, P.L. Richards, C.B. Eom ${ }^{a}$, T.H. Geballe ${ }^{a}$, S.M. Garrison ${ }^{\text {b }}$, N.

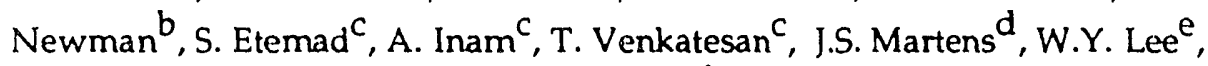 \\ L.C. Bourne ${ }^{f}$
}

Department of Physics, University of California, and Materials Sciences Division, Lawrence Berkeley Laboratory,Berkeley CA 94720

a Department of Applied Physics, Stanford University, Stanford CA 94305

b Conductus, Inc., Sunnyvale, CA 94086

c Bell Communications Research, Red Bank, New Jersey 07701

d Sandia National Laboratory, Albuquerque NM 87185

e IBM Almaden, San Jose CA 95120

f Superconductor Technologies, Santa Barbara CA 93111

This work was supported in part by the Director, Office of Energy Research, Office of Basic Energy Sciences, Materials Sciences Division of the U.S. Department of Energy under contract No. DE-AC03-76SF00098 (DM and PLR), by the AFOSR under contract No. F49620-88-C-004 (CBE and THG), and by the Center for Research in Superconductioity and Superconducting Electronics under contract No. F49620-88-C-001 (CBE and THG). 


\title{
Submillimeter and Microwave Residual Losses in Epitaxial Films of Y-Ba-Cu-O and Tl-Ca-Ba-Cu-O
}

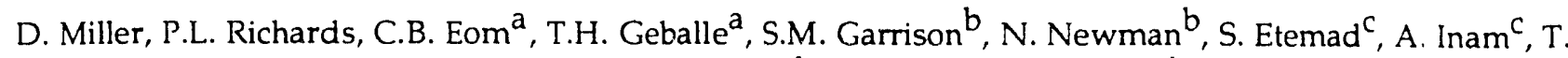 \\ Venkatesan $^{c}$, J.S. Martens ${ }^{d}$, W.Y. Lee ${ }^{e}$, L.C. Bourne ${ }^{f}$ \\ Department of Physics, University of California, and Materials Sciences Division, Lawrence Berkeley \\ Laboratory, Berkeley CA 94720 \\ a Department of Applied Physics, Stanford University, Stanford CA 94305 \\ b Conductus, Inc., Sunnyvale, CA 94086 \\ c Bell Communications Research, Red Bank, New Jersey 07701 \\ d Sandia National Laboratory, Albuquerque NM 87185 \\ e IBM Almaden, San Jose CA 95120 \\ f Superconductor Technologies, Santa Barbara CA 93111
}

\section{ABSTRACT}

We have used a novel bolometric technique and a resonant technique to obtain accurate submillimeter and microwave residual loss data for epitaxial thin films of $\mathrm{YBa}_{2} \mathrm{Cu}_{3} \mathrm{O}_{7}, \mathrm{Tl}_{2} \mathrm{Ca}_{2} \mathrm{Ba}_{2} \mathrm{Cu}_{3} \mathrm{O}_{10}$ and $\mathrm{Tl}_{2} \mathrm{CaBa}_{2} \mathrm{Cu}_{2} \mathrm{O}_{8}$. For all films we obtain good agreement between the subrnillimeter and microwave data, with the residual losses in both the $\mathrm{Y}-\mathrm{Ba}-\mathrm{Cu}-\mathrm{O}$ and $\mathrm{Tl}-\mathrm{Ca}-\mathrm{Ba}-\mathrm{Cu}-\mathrm{O}$ films scaling aproximately as frequency squared below $\sim 1 \mathrm{THz}$. We are able to fit the losses in the $\mathrm{Y}-\mathrm{Ba}-\mathrm{Cu}-\mathrm{O}$ films to a two fluid and a weakly coupled grain model for the $\mathrm{a}-\mathrm{b}$ plane conductivity, in good agreement with results from a Kramers-Kronig analysis of the loss data.

\section{EXPERIMENTAL APPROACH}

We have developed a novel technique for directly measuring the residual loss of high- $T_{C}$ thin films.[1] In this technique the high- $\mathrm{T}_{\mathrm{C}}$ film is used as the absorber in a composite bolometric detector for the signal from a Fourier transform spectrometer with a $\mathrm{Hg}$ arc source. Our technique allows us to obtain accurate direct absorptivity data on epitaxial $a-b$ plane films in the frequency range between microwave loss and infrared reflectivity measurements. The residual losses in the $\mathrm{YBa}_{2} \mathrm{Cu}_{3} \mathrm{O}_{7}$ films used for this study were also measured near $10 \mathrm{GHz}$ using microwave cavity techniques,[2] and are among the lowest reported in the literature. The residual losses in the $\mathrm{Tl}-\mathrm{Ca}-\mathrm{Ba}-\mathrm{Cu}-\mathrm{O}$ films used in this study were measured near $10 \mathrm{GHz}$ using microwave cavity techniques[2] and near 30 and $90 \mathrm{GHz}$ using a confocal resonator technique.[3] Using the well documented frequency squared dependence of the microwave loss up to $100 \mathrm{GHz},[4]$ we can infer the loss in our films over four decades in frequency.

\section{RESULTS}

The $a-b$ plane oriented $\mathrm{YBa}_{2} \mathrm{Cu}_{3} \mathrm{O}_{7}$ samples used in this study were grown on $\mathrm{MgO}$ and $\mathrm{LaAlO}_{3}$ substrates using off-axis sputtering $[5,6]$ and laser ablation techniques.[7, 8] These samples are notable for their lack of impurity phase and high degree of epitaxial alignment. The a-b plane oriented $\mathrm{Tl}_{2} \mathrm{CaBa}_{2} \mathrm{Cu}_{2} \mathrm{O}_{8}$ sample $\mathrm{S} 1$ was grown on a $\mathrm{LaAlO}_{3}$ substrate by laser deposition followed by a post deposition anneal,[9] and the mixed phase $\mathrm{Tl}_{2} \mathrm{Ca}_{2} \mathrm{Ba}_{2} \mathrm{Cu}_{3} \mathrm{O}_{10}$ and $\mathrm{Tl}_{2} \mathrm{CaBa}_{2} \mathrm{Cu}_{2} \mathrm{O}_{8}$ films $\mathrm{L} 1$ and $\mathrm{L} 2$ were grown on $\mathrm{LaAlO}_{3}$ substrates using an off-axis sputtering technique followed by a post-annealed with the amorphous 2:2:2:3 precursor films surrounded by $2: 2: 2: 3$ pellets in order to minimize $\mathrm{Tl}_{2} \mathrm{O}_{3}$ loss.[10] The results of our measurements are shown in Figs. 1 and 2.

\section{CONCLUSIONS}

We have characterized the residual loss in epitaxial $\mathrm{a}-\mathrm{b}$ plane films of $\mathrm{YBa}_{2} \mathrm{Cu}_{3} \mathrm{O}_{7}, \mathrm{Tl}_{2} \mathrm{CaBa}_{2} \mathrm{Cu}_{2} \mathrm{O}_{8}$ and mixed phase $\mathrm{T}_{2} \mathrm{Ca}_{2} \mathrm{Ba}_{2} \mathrm{Cu}_{3} \mathrm{O}_{10}$ and $\mathrm{Tl}_{2} \mathrm{CaBa}_{2} \mathrm{Cu}_{2} \mathrm{O}_{8}$ films from $10 \mathrm{GHz}$ to $21 \mathrm{THz}$. We do not observe any gap-like features below $15 \mathrm{THz}$ for any of the films studied. For all films studied the losses below $\sim 1 \mathrm{THz}$ scale approximately as frequency squared.

We have shown that the frequency dependence of the loss below $13.5 \mathrm{THz}$ for the $\mathrm{YBa}_{2} \mathrm{Cu}_{3} \mathrm{O}_{7}$ films can be well represented by a two fluid or a weakly coupled grain model.[1, 11] We find remarkable agreement between the results of a Kramers-Kronig analysis and the best fits from the weakly coupled grain model below $15 \mathrm{THz}$ for 
all film j.[12] These results suggest that weak link behavior may play a significant role in the microwave and submi'limeter losses.

We are unable to fit the losses in the Tl-Ca-Ba-Cu-O films either to the two fluid or to the weakly couple d grain models. We observe strong phonon structure in the Tl-Ca-Ba-Cu-O films between 1 and $21 \mathrm{THz}$. This is in strong contrast to the case for other high- $\mathrm{T}_{\mathrm{C}}$ superconductors such as $\mathrm{YBa}_{2} \mathrm{Cu}_{3} \mathrm{O}_{7}$, where phonon structure observed in ceramic samples is absent in epitaxial oriented films and crystals because of the electronic screening due to the high conductivity of the $a-b$ planes.

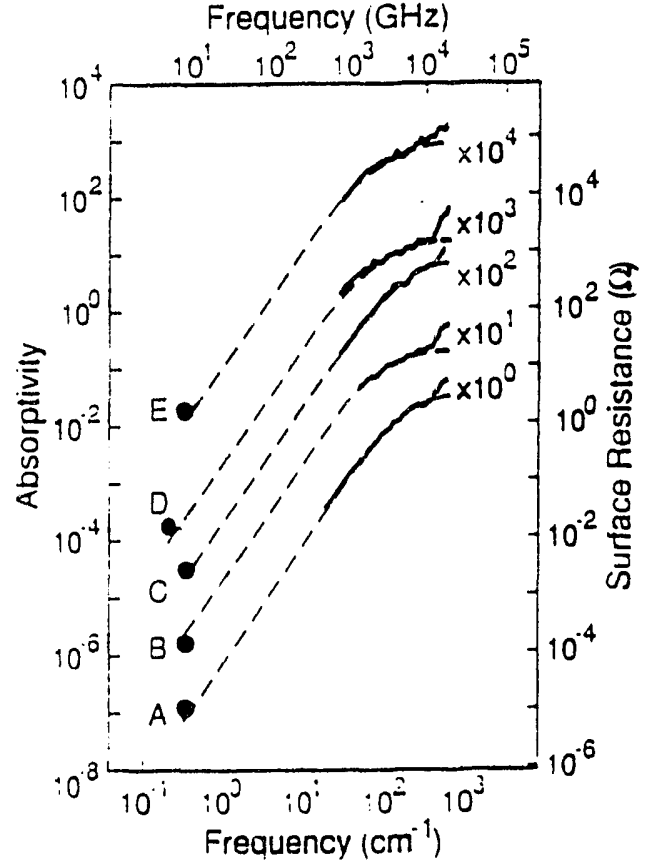

Fig. 1. Measured submillimeter absorptivities of samples $A$ through $E$ at $2 K$ (solid lines) multiplied by the indicated factors to separate the curoes. Values of the microwave surface resistance are shown as filled circles are measured for each sample at $4 \mathrm{~K}$ at the frequency indicated. Also shown are best fits to the weakly coupled grain model.

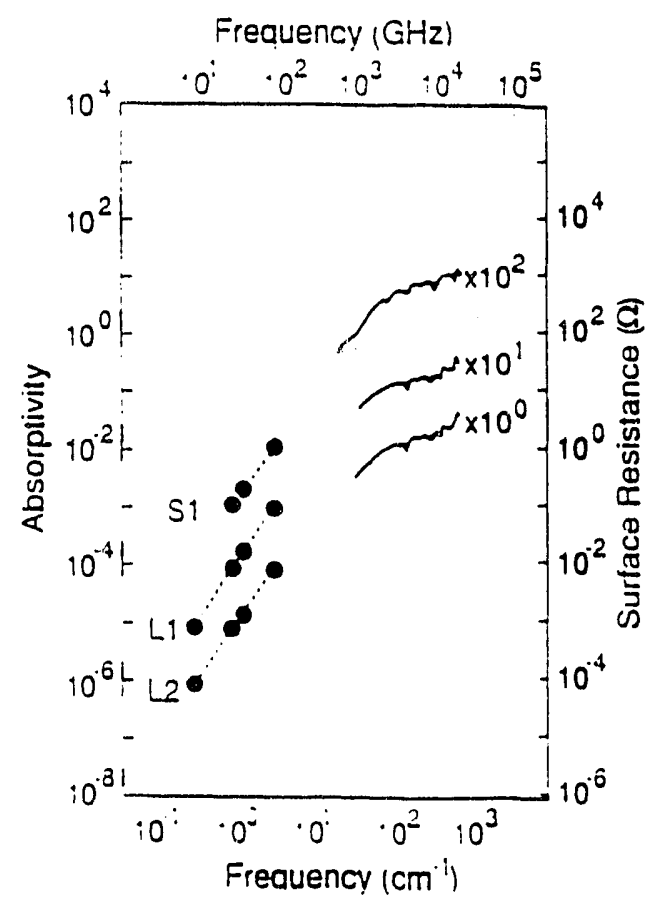

FIG. 2. Measured submillimeter absorptivities of samples L1, L2 and $S 1$ at $2 K$ (solid lines) multiplied by the indicated factors to separate the curoes. Values of the microwave surface resistance measured for each sample near $4 \mathrm{~K}$ are shown as filled circles. The dotted lines are best fits to the microwave surface resistance data using an $\omega^{2}$ dependence, where $\omega$ is the microwave frequency.

This work was supported in part by the Director, Office of Energy Research, Office of Basic Energy Sciences, Materials Sciences Division of the U.S. Department of Energy under contract No. DE-AC03-76SF00098 (DM and PLR), by the AFOSR under contract No. F49620-88-C-004 (CBE and THG), and by the Center for Research in Superconductivity and Superconducting Electronics under contract No. F49620-88-C-001 (CBE and THG).

[1] D. Miller, et al., Applied Physics Letters 59, 2326 (1991)

[2] R. C. Taber, Review of Scientific Instruments 61, 2200 (1990)

[3] J. S. Martens, et al., Applied Physics Letters 58, 2326 (1991)

[4] H. Piel, et al., IEEE Trans. Magn. 27, 854 (1991)

[5] N. Netvman, et al., Appl. Phys. Lett. 57, 520 (1990)

[6] C. B. Eom, et al., Appl. Phys. Leit. 55, 595 (1989)

[7! A. Inam, et al., Appl. Phys. Lett. 53, 908 (1988)

[8] D. M. Hwang, et al., Applied Physics Letters 54, 1702 (1989)

[9] R. B. Hammond, et al., Applied Physics Letters 57, 825 (1990)

[10] W. Y. Lee, et al., Applied Physics Letters 60, 772 (1992)

[11] T. L. Hylton, et al., Applied Physics Letters 53, 1343 (1988)

[12] D. Miller, et al., (submitted to Phys. Rev. B) 

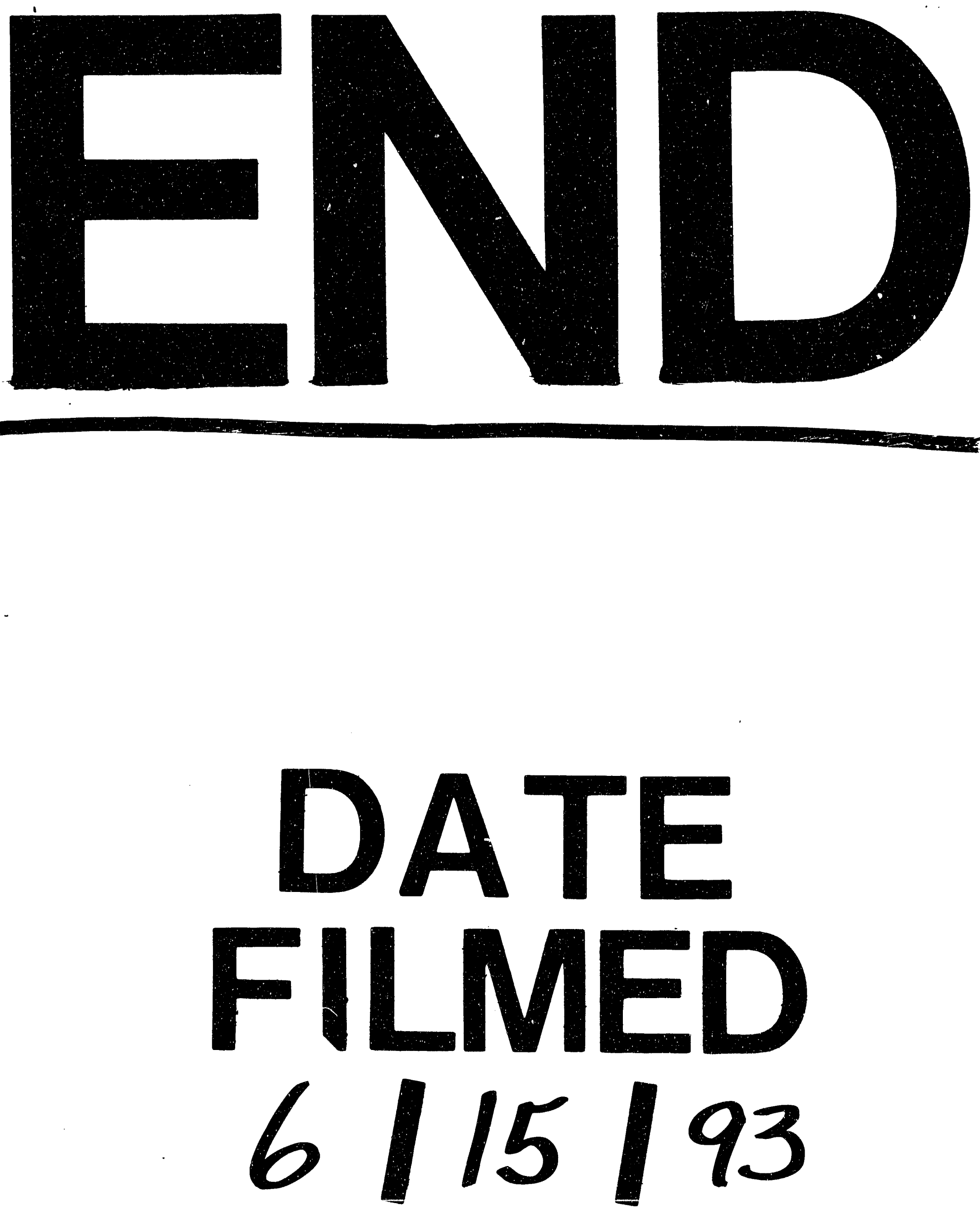

93 
